\title{
Advanced Space Transportation Concepts and Propulsion Technologies for a New Delivery Paradigm
}

\author{
John W. Robinson ${ }^{1}$ \\ Propellant Supply Technology, Seal Beach. California, 90740 \\ Carey M. McCleskey ${ }^{2}$ and Russel E. Rhodes (ret.) ${ }^{3}$ \\ NASA Kennedy Space Center, Florida, 32899 \\ Roger A. Lepsch ${ }^{4}$ \\ NASA Langley Research Center, Hampton, Virginia, 23681 \\ Edward M. Henderson (ret.) ${ }^{5}$ \\ NASA Johnson Space Flight Center, Houston, Texas, 77058 \\ Claude R. Joyner II ${ }^{6}$ \\ Pratt \& Whitney Rocketdyne, West Palm Beach, Florida, 33410 \\ Daniel J. H. Levack ${ }^{7}$ \\ Pratt \& Whitney Rocketdyne, Canoga Park, California, 91309
}

\begin{abstract}
This paper describes Advanced Space Transportation Concepts and Propulsion Technologies for a New Delivery Paradigm. It builds on the work of the previous paper "Approach to an Affordable and Productive Space Transportation System". The scope includes both flight and ground system elements, and focuses on their compatibility and capability to achieve a technical solution that is operationally productive and also affordable. A clear and revolutionary approach, including advanced propulsion systems (advanced LOX rich booster engine concept having independent LOX and fuel cooling systems, thrust augmentation with LOX rich boost and fuel rich operation at altitude), improved vehicle concepts (autogeneous pressurization, turbo alternator for electric power during ascent, hot gases to purge system and keep moisture out), and ground delivery systems, was examined. Previous papers by the authors and other members of the Space Propulsion Synergy Team (SPST) focused on space flight system engineering methods, along with operationally efficient propulsion system concepts and technologies. This paper continues the previous work by exploring the propulsion technology aspects in more depth and how they may enable the vehicle designs from the previous paper. Subsequent papers will explore the vehicle design, the ground support system, and the operations aspects of the new delivery paradigm in greater detail.

\footnotetext{
${ }^{1}$ Propellant Supply Technology; chairman, Space Propulsion Synergy Team, and AIAA Associate Fellow.

${ }^{2}$ Aerospace Technologist, Engineering and Technology Directorate, NASA Kennedy Space Center, Mail Code NE-D3; AIAA Senior Member.

${ }^{3}$ Aerospace Technologist, NASA Kennedy Space Center, retired, and AIAA Senior Member.

${ }^{4}$ Aerospace Technologist, Systems Analysis and Concepts Directorate, NASA Langley Research Center, Mail Stop 451.

${ }^{5}$ NASA/JSC Space Shuttle Program, Advanced Studies, retired, and AIAA Associate Fellow.

${ }^{6}$ Fellow, Systems Analysis, P.O. Box 109600 MS712-67, AIAA Associate Fellow.

${ }^{7}$ Program Manager, Advanced Programs, P.O. Box 7922 / MS RFB19, AIAA Member.
} 


\section{Nomenclature}

\begin{tabular}{|c|c|}
\hline ACS & $=$ Attitude Control System \\
\hline $\mathrm{C}^{*}$ & $=$ Characteristic Velocity \\
\hline ET & $=$ Expendable Tank \\
\hline FFSC & $=$ Full Flow Staged Combustion \\
\hline GG & $=$ Gas Generator \\
\hline GLOW & $=$ Gross Lift Off Weight \\
\hline GSE & $=$ Ground Support Equipment \\
\hline $\mathrm{H}_{2}$ & $=$ Hydrogen \\
\hline Isp & $=$ Specific Impulse \\
\hline JSC & $=$ Johnson Space Flight Center \\
\hline LEO & $=$ Low Earth Orbit \\
\hline $\mathrm{LH}_{2}$ & $=$ Liquid Hydrogen \\
\hline $\mathrm{LO}_{2}$ & $=$ Liquid Oxygen \\
\hline LOX & $=$ Liquid Oxygen \\
\hline MSFC & $=$ Marshall Space Flight Center \\
\hline NASA & $=$ National Aeronautics and Space Administration \\
\hline $\mathrm{O}_{2}$ & $=$ Oxygen \\
\hline OMS & $=$ Orbital Maneuvering System \\
\hline PWR & $=$ Pratt \& Whitney Rocketdyne \\
\hline $\mathrm{RCB}$ & $=$ Reusable Cryogenic Booster \\
\hline $\mathrm{RCO}$ & $=$ Reusable Cryogenic Orbiter \\
\hline $\mathrm{RCS}$ & $=$ Reaction Control System \\
\hline SPST & $=$ Space Propulsion Synergy Team \\
\hline TVC & $=$ Thrust Vector Control \\
\hline U.S. & $=$ United States \\
\hline
\end{tabular}

\section{Introduction}

At the 2012 Joint Propulsion Conference the paper "Approach to an Affordable and Productive Space Transportation System"1 was presented. That paper described an approach for creating space transportation architectures that are affordable, productive, and sustainable. The architectural scope included both flight and ground system elements, and focused on their compatibility to achieve a technical solution that is operationally productive, and also affordable throughout their life cycle. The paper presented and used a structured process to derive examples of conceptual architectures that integrated a number of advanced concepts and technologies.

This paper continues the previous work in the area of the "propulsion" aspect of the vehicle design. Subsequent papers will explore other aspects of the vehicle design, the operations, and the architecture.

In the previous paper two vehicle approaches were defined. Propulsion choices were made based on Reference 2, but without explanation as to why. No actual schematic or engine balances were developed. This paper will go through those steps and will also fly notional trajectories using the engine design developed. 
By "propulsion" it is meant that every function associated with propelling the vehicle is examined for functional synergy: the main propulsion function, the ACS/RCS function, the orbital maneuvering (OMS) function, the propellant pressurization function, the purging function, the valve and thrust vector control (TVC) actuation function, and the generation of electrical power function. Most of these functions are implemented by separate systems on conventional vehicles. The overall cost of the entire transportation architecture can be greatly reduced if these functions are instead designed as one integrated system. This approach allows trades among the parameters of the functions and sharing of hardware among the functions, instead of letting each function optimize within itself only while matching specified interfaces. This latter approach results in too many different fluids, stored at too many different sets of conditions, in too many different places, and with excess interfaces. It does not allow the use of the same piece of hardware (not even two copies of the same hardware) to be used in performing more than one function. And it prevents the trading of parameters within different functions which are needed to help produce a more optimum system.

\section{Overall Design Description}

Reference 1 presented two vehicle concepts: a reusable vehicle with a booster and an identical orbiter sharing an expendable propellant tank, and a bimese vehicle system with similar reusability but with only expendable hydrogen tanks. Concept depictions are shown in Figure 1. The operability discussion that follows will focus on the configuration architecture that uses a reusable booster and orbiter with an external tank.

Both the booster and the orbiter carry propellant, but the majority of the propellant is in the expendable tank. The notional

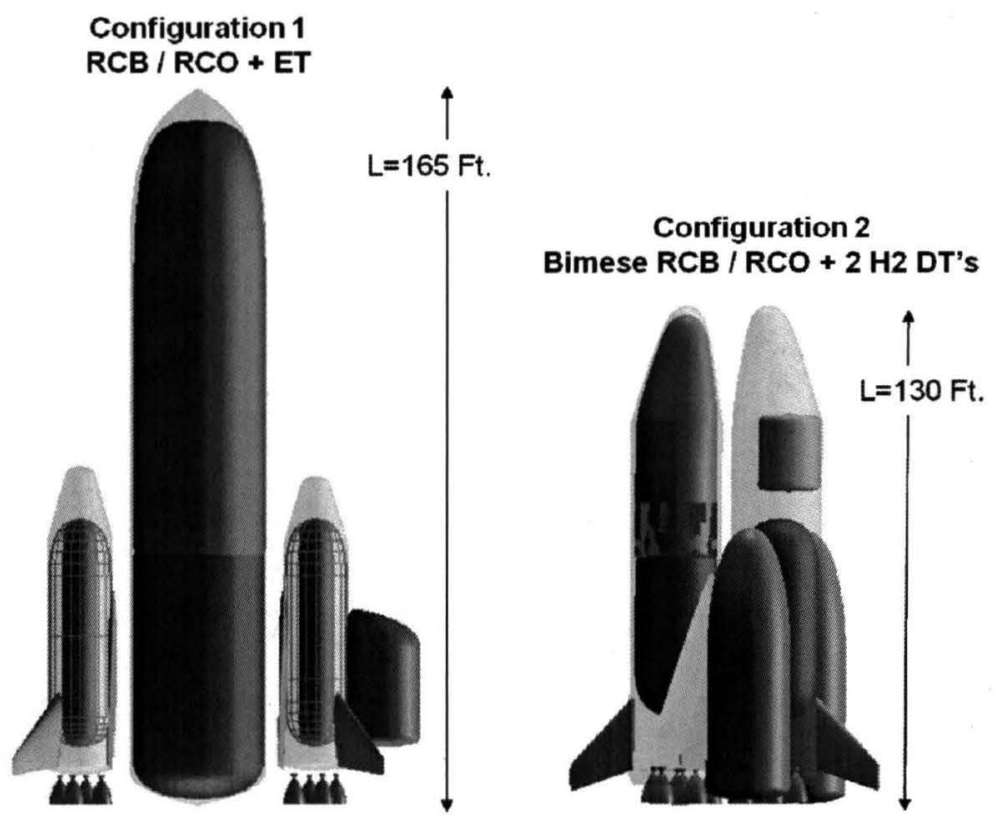

Figure 1. Notional Vehicle Designs Considered flight operational concept is shown in Figure 2. During the first phase both the booster and the orbiter fire at an ox-rich mixture ratio to maximize thrust during the early part of the flight. The booster separates and returns at the end of this phase. During the second phase the orbiter continues to draw propellants from the external tank and shifts to a fuel rich mixture ratio to improve specific impulse. The external tank is released and disposed of at the end of this second phase. Finally the orbiter alone finishes the LEO orbit insertion phase placing 55,125 pounds of payload plus a payload pod of $17,400 \mathrm{lbm}$ into LEO. The gross lift off weight calculated for this configuration in Reference 1 was about 3.3 million pounds and that value was used for sizing the propulsion in this paper. 


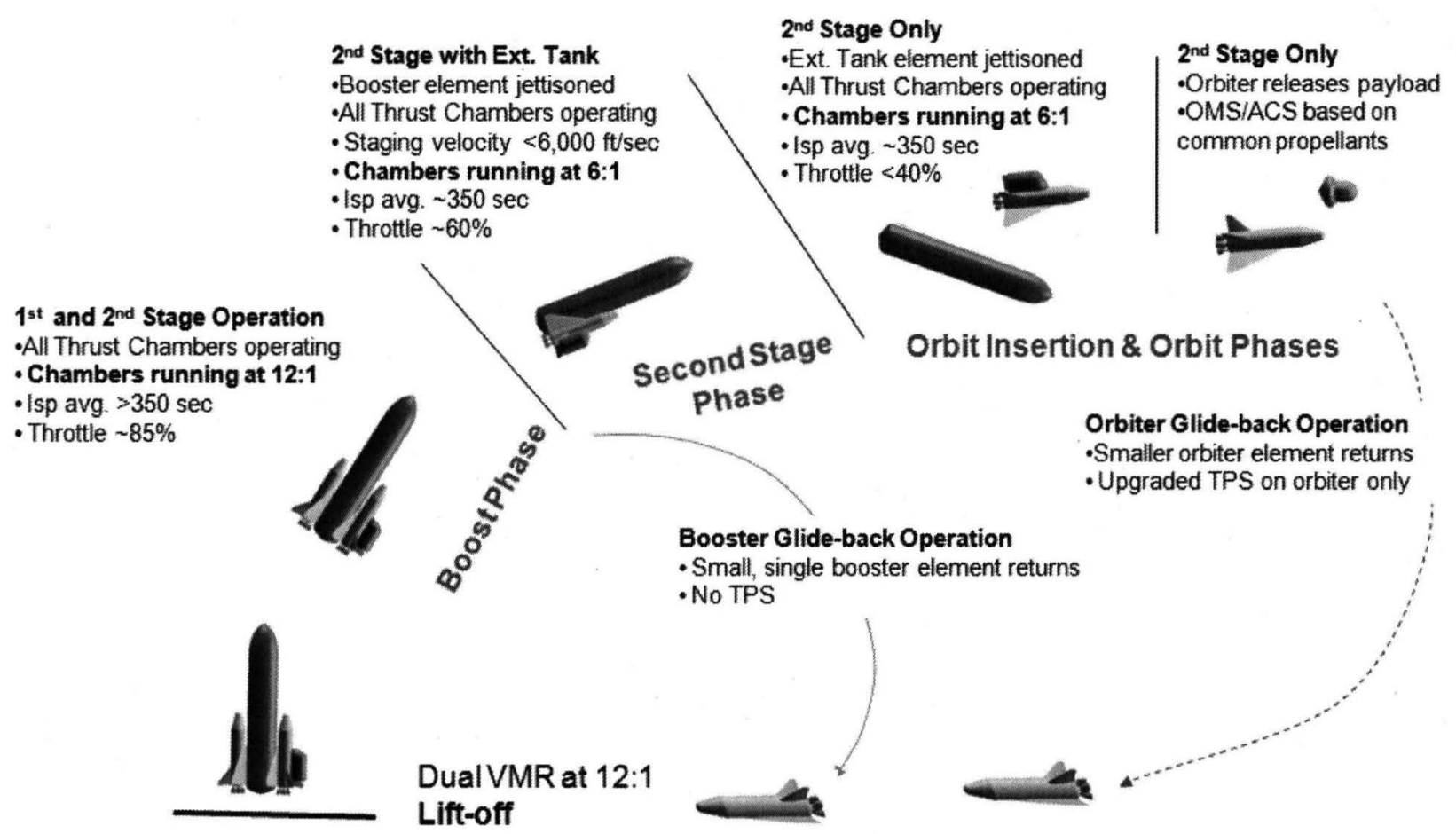

Figure 2. Notional Flight Operational Concept-RCB/RCO+ET

\section{Propulsion Choices}

Designing the "propulsion" aspect of the vehicle for support - a necessary condition for producing an affordable space transportation architecture - requires considering the entire architecture to determine the drivers that need to be pursued in the design. Consideration of the entire architecture - operations, vehicle, and propulsion systems - led to several drivers in the choice of propulsion systems and electric power generation system characteristics. They are:

1. Attain the performance needed for the defined vehicle configuration;

2. Reduce the number of different fluids;

3. Reduce the number of toxic fluids;

4. Increase system margins;

5. Reduce the number of different propulsion systems;

6. Reduce the number of purges;

7. Reduce the number of Crit-1 failure modes;

8. Reduce the number of different vehicle systems.

The first driver is actually a requirement and must be met. The others are means to reducing the overall cost of the architecture both in the development and the operational phases. The costs are reduced by decreasing the number of contracts and contractors, allowing more effective and efficient trades during the design phase, and, especially, by reducing the operating costs through reducing the logistics needed. 


\section{Choice of Propellants}

Configurations, such as the ones in this paper, in which all main propulsion elements burn throughout the flight, each until it is staged off or the vehicle reaches LEO, require higher specific impulse than configurations where the elements only burn sequentially and are then staged off. If an all $\mathrm{LO}_{2} / \mathrm{RP}$ propellant choice is made for both the booster and the orbiter, the concept will not satisfy the performance requirement. If $\mathrm{LO}_{2} / \mathrm{RP}$ is used on the booster and $\mathrm{LO}_{2} / \mathrm{LH}_{2}$ on the orbiter the performance could be satisfied, but that would require having different fluids and increasing the number of different propulsion systems, violating drivers 2 and 5. The design does close using $\mathrm{LO}_{2} / \mathrm{LH}_{2}$ for both the booster and the orbiter and drivers 2 and 5 are satisfied.

The drawback is that the bulk density is low, but the bulk density can be improved by using different mixture ratios at different points in the flight trajectory, which will make the design easier to close. The bulk density is the effective density that is determined by actual oxidizer and fuel densities and the mixture of those relative to the propulsion system operation. For example when $\mathrm{LO}_{2} / \mathrm{LH}_{2}$, with densities of 70 and 4.42 pounds per cubic foot respectively, is supplied to the propulsion system at a mixture ratio of $6: 1$ the effective bulk density for the propellants is 22.5 pounds per cubic foot.

Because of the major difference in density impulse, $\mathrm{LO}_{2}$ /hydrocarbon vehicles must carry a higher mass of propellant than $\mathrm{LO}_{2} / \mathrm{LH}_{2}$ vehicles, which results in as much as a 20 percent higher GLOW, and therefore requires 20 percent higher thrust at liftoff. Figure 3 illustrates results of a previous trade study comparing relative costs of vehicles for three propellant combinations.

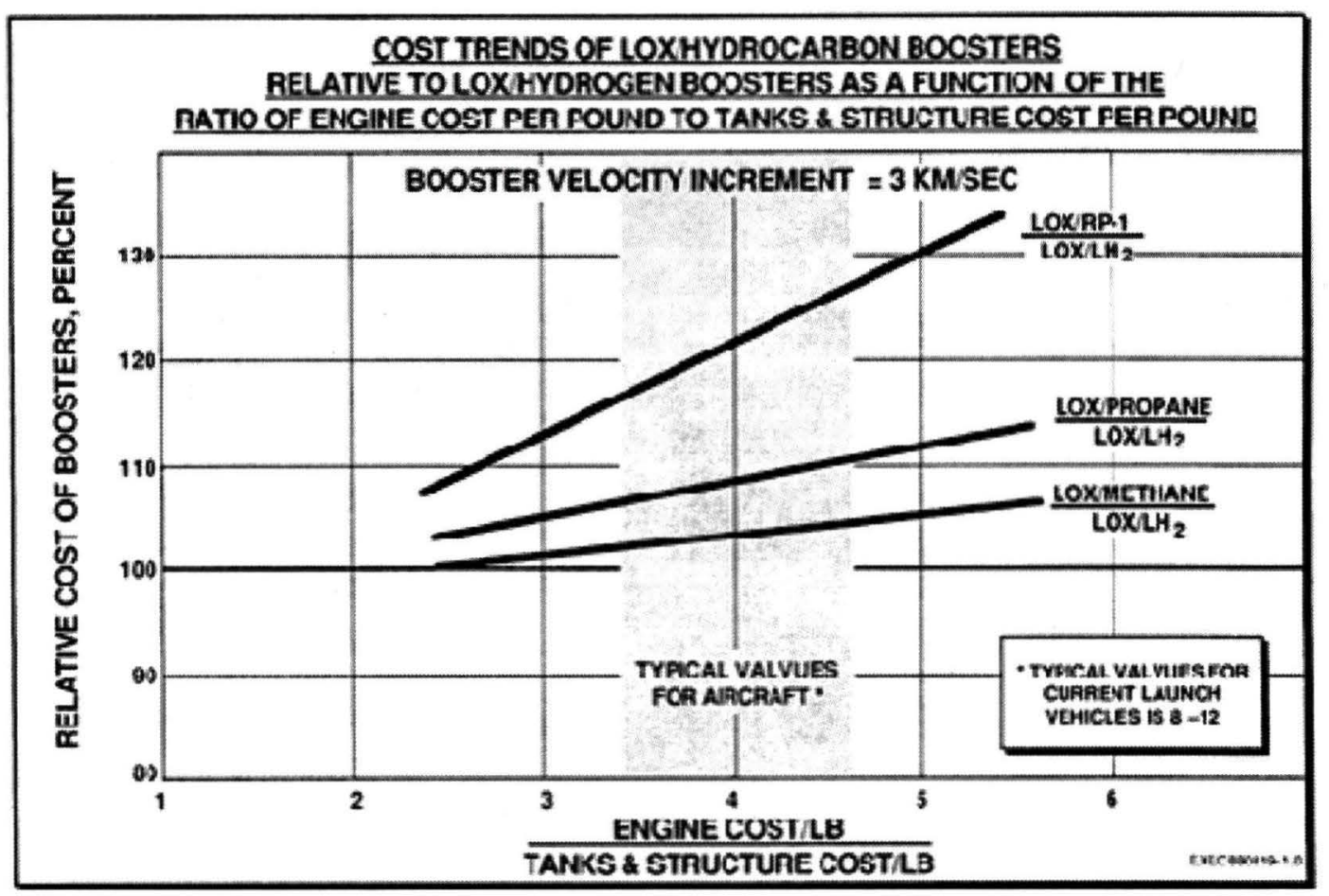

Figure 3. Relative Costs of Boosters Show Effect of Increased Liftoff Thrust Requirement 
In that study the penalty for carrying the higher propellant mass at liftoff was clearly illustrated. Not readily apparent is that the large engines were oversized near staging and needed to be throttled back, further penalizing performance and mission cost. In Figure 4 a logic chart is provided for making a propellant selection. Basically two design optimization paths are shown. One is "Low Dry Weight", the other is "Low GLOW".

The "Low Dry Weight" path requires $\mathrm{LO}_{2} /$ Hydrocarbons to achieve the small tankage. It also drives the engines to high chamber pressures and higher turbine temperatures, and to the GG cycle for the $\mathrm{LO}_{2} /$ hydrocarbon version. The $\mathrm{LO}_{2} / \mathrm{LH}_{2}$ version, using a mixture ratio of around 9-12 and the full flow staged combustion cycle (FFSC), can be shown to be competitive with the $\mathrm{LO}_{2}$ /hydrocarbon version. Following the "Low GLOW" option it is observed that the high Isp also contributes to a competitive thrust to weight, but more importantly the reduced liftoff propulsion demand represents a major savings in propulsion system cost. Continuing on across the logic chart, the further important observation is that use of $\mathrm{O}_{2} / \mathrm{H}_{2}$ in the booster stage contributes to overall vehicle system simplicity and commonality, as well as significantly simplifying ground operations and ground support equipment (GSE).

$\mathrm{LO}_{2} / \mathrm{LH}_{2}$ was chosen for the booster and the orbiter.

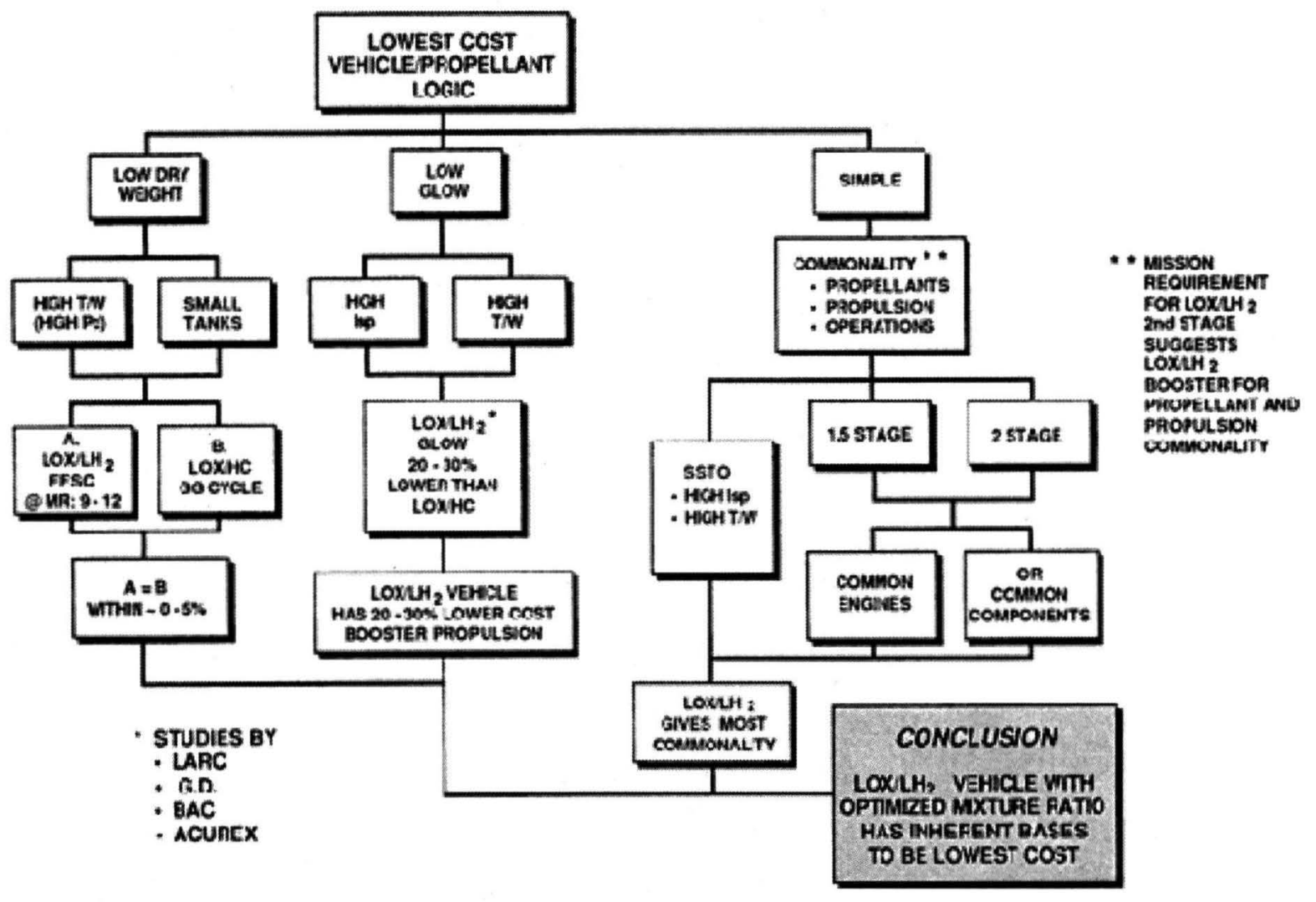

Figure 4. Propellant Selection Logic 


\section{Mixture Ratio Choice}

At lift off maximum thrust is desired, but as the flight continues through the trajectory and the vehicle weight is decreased due to propellant use, the emphasis shifts to maximum specific impulse to minimize the overall vehicle weight. This is often addressed by using $\mathrm{LO}_{2} / \mathrm{RP}$ for the booster and $\mathrm{LO}_{2} / \mathrm{LH}_{2}$ for the orbiter. However, as discussed above, this vehicle uses $\mathrm{LO}_{2} / \mathrm{LH}_{2}$ for both the booster and the orbiter in order to obtain the benefits of a simpler architecture to design, produce, and operate. Nonetheless, higher thrust operation can be obtained in an $\mathrm{LO}_{2} / \mathrm{LH}_{2}$ engine by running the engine at an ox-rich mixture ratio. Consequently, the engines are run at a mixture ratio of 12 during the first phase of the flight, and then switched over to operation at a mixture ratio of 6 . The split of 12 and 6 mixture ratio operation provides an average 8:1 for the vehicle architectures and increases the volumetric efficiency with hydrogen, versus sizing only for a $6: 1$ mixture ratio, to get higher performance. Using a variable mixture ratio for a $\mathrm{LO}_{2} / \mathrm{LH}_{2}$ propulsion system provides more synergism with the vehicle and provides a foundation for a reusable launch system that is more capable, effective, and operable.

The thrust chambers are cooled only by the hydrogen. Since the hydrogen is sufficient to cool the thrust chambers even at the mixture ratio of 12 , when the hydrogen is at a minimum, the hydrogen will also be sufficient at the mixture ratio 6 operating point. A small amount $(\sim 0.5 \%$ to $2 \%$ ) of the oxygen is regeneratively heated to provide re-pressurization flow and a source of gas for turbine shut down purges. The most likely location is the oxidizer preburner. This location avoids a hot $\mathrm{H}_{2}$ heat exchanger for the $\mathrm{O}_{2}$ and, since the preburner does not actually need to be cooled, it is not sensitive to varying amounts of $\mathrm{O}_{2}$.

\section{Pressurization}

Consideration of drivers 2 and 8 - reducing the number of different fluids and vehicle systems - leads to the choice of autogenous pressurization. This means using the gasified oxygen and hydrogen downstream of the pumps to pressurize the oxygen and hydrogen tanks. If both of the propellants are used for regenerative cooling, then they can be directly tapped-off for pressurant gases. If only one fluid were used for regenerative cooling, then a heat exchanger would be needed for the small amount of fluid that is needed on the propellant side not used for cooling. That is why the oxidizer preburner is used to regeneratively heat a small amount of $\mathrm{O}_{2}$.

\section{Main Engine Power Cycle Choice}

The choice of the main engine power cycle is impacted first and foremost by the need to meet the stringent specific impulse requirements of this vehicle design. Such a design stresses the ability of the cycle to get as much specific impulse as possible, which, in turn, pushes the need for a fairly high chamber pressure to achieve a moderately high nozzle area ratio.

Also important is the drive to increase the system margins, reduce the purges (particularly if they use a different gas), reduce the number of Crit-1 failure modes, and to reduce the number of different vehicle systems; i.e., consideration of drivers $4,6,7$ and 8 . These drivers can best be pursued with power cycles that do not require interpropellant seals and that use turbine inlet 
temperatures as low as possible. Cycles that do not require interpropellant seals can eliminate a major Crit-1 failure mode and reduce the amount of purges needed. They may be able to selfpurge which would eliminate an entire vehicle system.

Only four cycles have no interpropellant seal requirements. They are open or closed dual expander cycles, the dual gas generator open cycle, and the full flow staged combustion closed cycle.

The dual expander cycles use heated fuel to power the fuel turbine and heated oxidizer to power the oxidizer turbine. The expander cycle is a fairly simple cycle but, because it does not use combustion to heat the turbine fluids, it is limited in the chamber pressure it can reach at any given thrust level. The chamber pressure that will be discussed below (2,640 psi) is too high, at the thrust chosen, to have confidence that this cycle can achieve the needed chamber pressure.

The dual gas generator cycle, where ox-rich gases drive the oxidizer turbine and fuel-rich gases drive the fuel turbine, can reach the pressures needed, but it is an open cycle with significant specific impulse losses compared to a closed cycle. If this were a sequential burn two stage vehicle, the dual gas generator cycle might be applicable. However, this is a parallel burn two stage vehicle and closing the vehicle design is very sensitive to the specific impulse value.

The full flow staged combustion cycle can reach the chamber pressure chosen. Only oxidizer-rich gases flow on the oxidizer side of the engine, and only fuel-rich gases flow on the fuel side of the engine. Because it has the most power available of any power cycle, it can use the lowest turbine temperatures, which, in turn, increases system margins.

Although a parallel burn two stage configuration with all chambers providing thrust at liftoff further enhances performance by minimizing or avoiding base drag in the atmosphere, nevertheless, it is appropriate to take advantage of the FFSC cycle to provide as much performance as practical.

In this cycle the low turbine temperatures, abundance of cooling, benign turbine temperatures, simplicity of design throughout and the accessibility of high performance at moderate chamber pressure and moderate chamber heat transfer parameters, provide the desired environment to improve reliability and increase margins. The high turbine mass flows support a fairly high chamber pressure to achieve a moderately high nozzle area ratio. The propellants enter the main combustion chamber as pre-burned combustion products and so mix and burn more readily than liquid phase propellants. This promotes high $\mathrm{C}^{*}$ efficiency while avoiding mixing problems to improve specific impulse.

A further important attribute of the FFSC cycle is that there are compatible drive gases available to drive the boost pumps. This allows the main pumps to operate at higher inlet pressures. It also allows the propellant tanks to operate at lower pressures saving pressurant gas and allowing reduced tank wall thickness. A further benefit is that the inlet system can be operated outside the region in which pogo phenomenon is encountered and the entire POGO system may be eliminated.

The full flow staged combustion cycle was chosen for this conceptual design. Figure 5 provides a sample cycle schematic representative of the full flow staged combustion engine cycle 
selected for further discussion and examination. The chamber pressure is 2,640 psi at design operating point using a fuel turbine inlet temperature of $1,500^{\circ} \mathrm{R}$ and an oxidizer turbine inlet temperature of $1,300^{\circ} \mathrm{R}$. The full flow staged combustion cycle has been developed and tested, but it has not been flown.

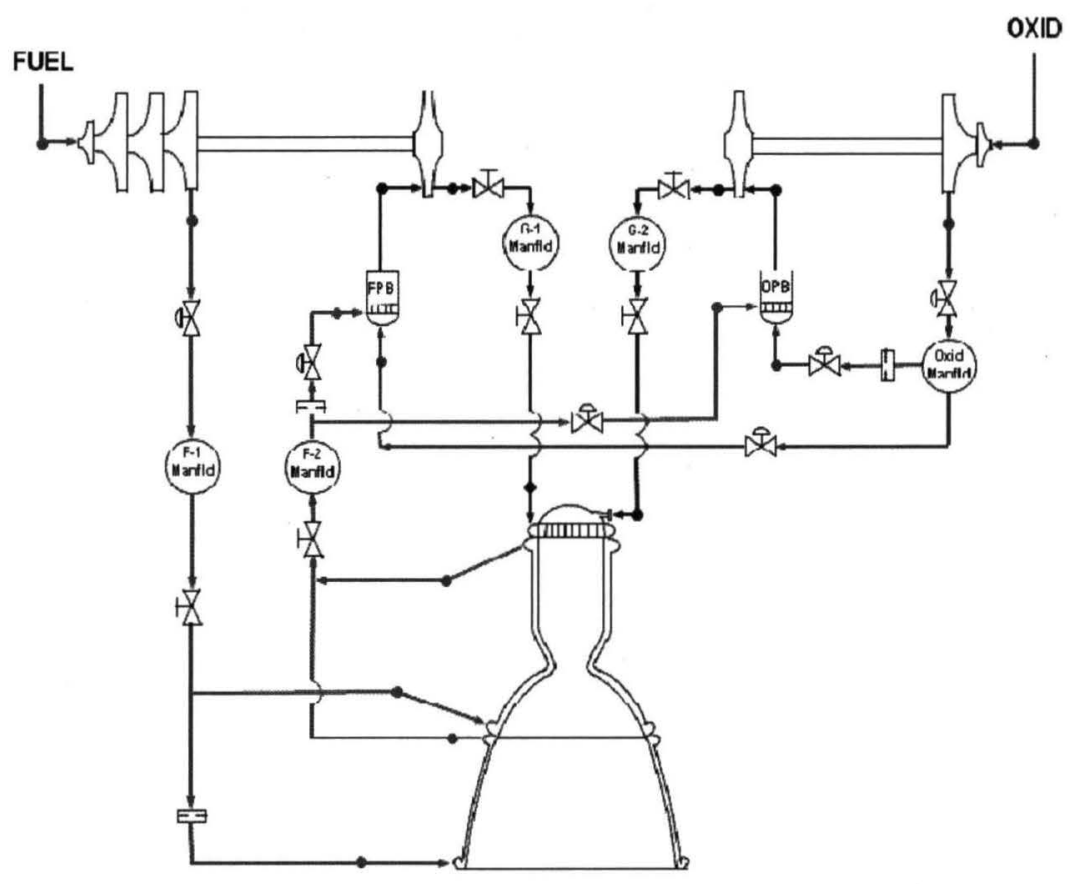

Figure 5. Notional Full Flow Staged Combustion Cycle Schematic

\section{Purges}

Purging will not be eliminated; however, using a separate purging fluid can be eliminated. Because only oxidizer-rich gases flow on the oxidizer side of the engine, and only fuel-rich gases flow on the fuel side of the engine, the preburner valves can be shut down such that the water production stops and a final like-side warm gas flow occurs.

\section{ACS/RCS System Choices}

Consideration of drivers 2,3 , and 5 - reducing the number of different fluids, toxic fluids, and different propulsion systems - leads to using $\mathrm{O}_{2} / \mathrm{H}_{2}$ as the ACS/RCS propellants. It also leads to tanking the ACS/RCS propellants in the same tanks as the main propulsion system propellants. Whether the thrusters are liquid/liquid, gas/liquid, or gas/gas and whether the thrusters are uncooled or regeneratively cooled with one fluid or both fluids, is a subject for the design phase. A method to increase the pressure for the ACS/RCS propellants is probably needed. An electric pump followed by an accumulator is a potential solution. The use of the accumulator will partially decouple the design requirements of the pump from the requirements of the thrusters. 
The choice of tanking the ACS/RCS propellants in the same tanks as the maim propellants will delete several stand-alone flight propellant and pressurant tanks, will also delete ground and flight servicing hardware for all of these stand-alone vessels, and will result in a very large support infrastructure reduction, both at the launch site and for manufacturing/sustaining engineering. This reduction of systems will result in a large part count reduction and add reliability, increase safety, and reduce life cycle cost. This approach may lend itself to enabling the use of presently un-usable propellant following the ascent phase of flight. If the system is reusable, the ground servicing time for the ACS/RCS function between flights will be significantly reduced.

\section{OMS System Choices}

Consideration of the same drivers $(2,3$, and 5$)$ leads to using the main engines to perform the OMS function. Two methods, which would have to be traded during the design phase, are available - using a tank head start and operating in that mode (idle mode) for OMS operation, or deeply throttled operation.

Idle mode operation is simply running the engine as a pressure-fed engine. The propellants bypass the pumps and turbines and are ignited in the main thrust chamber. The thrust is quite low. Although the cooling fluid is low, the heat flux is also very low. The J-2S, RL10, and the LE-5B were or are all capable of idle mode operation.

Deeply throttled operation is an alternative and, for example, the J-2S and the RL10 have shown stable operation below $10 \%$ of nominal thrust.

The lack of a separate OMS will eliminate an entire engine development program. It will also delete several stand-alone flight propellant and pressurant tanks, will also delete ground and flight servicing hardware for all of these stand-alone vessels, and will result in a very large support infrastructure reduction, both at the launch site and for manufacturing/sustaining engineering. This reduction of systems will result in a large part count reduction and add reliability, increase safety, and reduce life cycle cost.

\section{Electrical Power Generation}

The electrical power needed by the vehicle can be carried in batteries or fuel cells, can be generated on the fly as needed, or some combination of both approaches. Consideration of drivers 2, 3, and 8 - reducing the number of different fluids, toxic fluids, and different vehicle systems - strongly suggests the use of the propellants to generate electric power. Since it has already been decided that the tanks will be autogenously pressurized, there is available a supply of high pressure fluid on both the oxygen and hydrogen sides to run turbo-alternators to generate electrical power. The pressure in both these lines has to be reduced prior to using it for pressurization, and that pressure reduction powering a turbine in a turbo-alternator is an ideal fit.

The drawback to this approach is that it is only available when the main propulsion system is operating. An alternative is to use residual and/or pressurant gases from the tanks to run a turbo- 
alternator. This method works even when the main propulsion system is not operating but it produces less power.

A battery or fuel cell would still be needed. It acts as an accumulator and would be much smaller than the battery or fuel cell required without the turbo-alternators.

During the design phase a trade should be performed to size the turbo-alternator and battery/fuel cell subsystems and to decide if all three are useful in a given application.

\section{Valve and Thrust Vector Control Actuation}

The valves in the system can be actuated in many ways and are typically activated hydraulically or pneumatically. However, such a choice would add fluids to the system. Consideration of driver 2 (reduce fluids), and noting that the system will generate electrical power, strongly suggests the use of electromechanical actuators for both the valves and the thrust vector control.

\section{Turbopump and Thrust Chamber Configurations}

The traditional U.S. approach is to build engines with a single set of turbopumps feeding a single thrust chamber assembly. There are alternate approaches. A single turbopump set can feed multiple thrust chamber assemblies (some Russian engines operate this way, as did the U.S. MA-5/5A); multiple turbopump sets can feed a single thrust chamber assembly; multiple turbopump sets can be associated with multiple thrust chamber assemblies using ring manifolds where no particular turbopump set (or even individual turbopump) is associated with a particular thrust chamber assembly ${ }^{3,4,5}$.

In order to increase system margins as much as possible (driver 4), the last approach will be used for this design. Assume for the moment a vehicle with six engines. Using the traditional approach, if one turbopump fails on one engine and one thrust chamber fails on another engine, then two of the six engines are off line and only four are available. Using the ring manifold approach, if one turbopump fails and one thrust chamber fails, then five independent turbopumps and five independent thrust chambers are still available. Only the equivalent of one engine is off line because individual turbopump sets (or even individual turbopumps) and individual thrust chamber assemblies can be isolated such that their failures do not take the engine off line. Figure 6 shows a notional configuration using this approach. 


\section{LOX AND $\mathrm{LH}_{2}$ PUMPING MODULES}

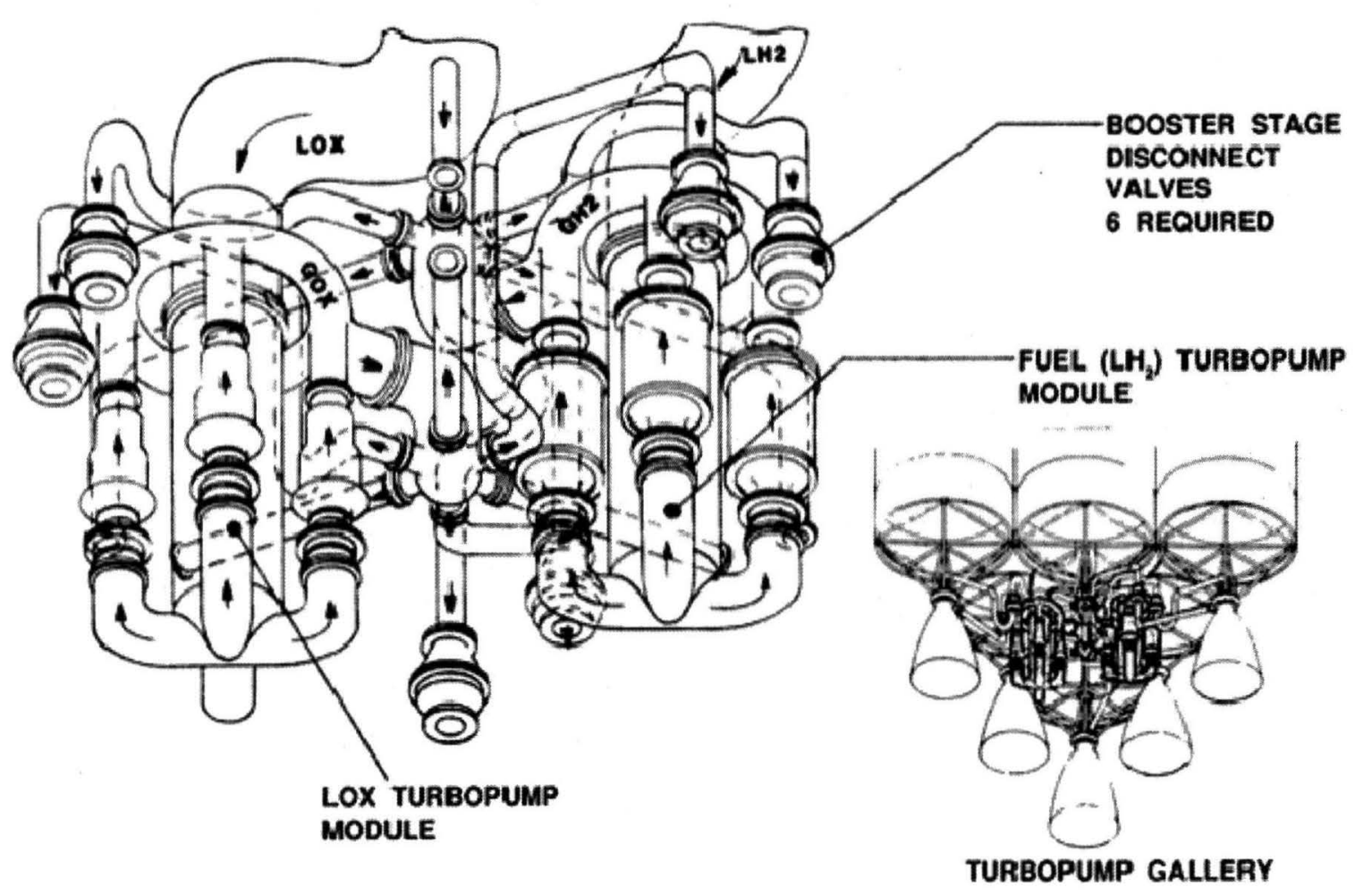

Figure 6. Example Turbopump Modules, All Turbopumps Feed All Chambers

\section{Turbopump Placement}

Since the turbopumps are separate from the thrust chambers in the concept chosen, they can be located in a tank sump next to the propellant tanks. With this location the fill and drain can be directly into the sump avoiding extended cool-down and allowing faster propellant servicing. This location deletes the requirement for anti-geysering, pogo, and pump conditioning systems for engine start. The location also deletes traditional pre-valves, therefore saving weight, increasing safety of flight, reliability, and reducing recurring cost.

However, this location does require longer lines for the high pressure fluid flows from the pumps to the thrust chambers and for the fluids from the thrust chambers to the preburners thus increasing weight. It also places hot gas much nearer to the propellant tanks. Pump failure cannot be isolated from propellant in the tank and that would require safety measures at stage element test facilities.

Driver 8 (reduce number of different systems) suggests the sump location and the operational gains are significant and thus the choice is to locate the turbopumps in sumps at the propellant tanks. 


\section{Thrust Level, Number of Engines, Chamber Pressure, and Area Ratio}

Because the vehicles can range from a stage-and-a-half design to bimese or other two stage reusable configurations, the main propulsion system must operate at sea level and at vacuum. This impacts the choice of the nozzle area ratio. It must be a compromise between low enough to have high thrust at sea level and high enough to have good specific impulse at vacuum. The area ratio must also be such that, with the chamber pressure chosen, the flow does not separate at sea level. The Space Shuttle Main Engine (SSME) operated in a two stage-and-expendable tank vehicle design and used an area ratio of 69 . If an area ratio of 69 is chosen, then the chamber pressure should be about 2,200 psi or higher to avoid separation at sea level. Consequently, the area ratio of 69 was chosen and a minimum operating chamber pressure of 2,200 psi was chosen.

An engine out capability would be very useful for mission assurance if it can be reasonably implemented. Thus, the number of engines must be reasonably high so that when one engine is out, the increase in thrust required from the other engines is not excessive. The number is obviously something that should be traded in the design phase, but six was chosen for this paper. The choice of six engines means that the engine design point will be $20 \%$ higher in thrust and chamber pressure than the nominal operating point. This has the additional benefit of improving driver 4 (improve system margins). Consequently, the six engines were designed for a chamber pressure of 2,640 psi.

Another design aspect that is coupled between the vehicle and the propulsion design characteristics is the acceleration limit imposed due to structural or payload constraints. For common propulsion approaches that facilitate the highest operability efficiency the throttle range will be large. If the propulsion design is sized for one mixture ratio to deliver the required lift-off thrust, then "steps" down to a lower mixture ratio, the system is at or lower than $50 \%$ of the original level for the $\mathrm{LO}_{2} / \mathrm{LH}_{2}$ propulsion discussed in this paper. When the second stage or orbiter element attains the acceleration limit for that phase of flight, the propulsion needs to shut down thrust chambers or throttle even more. Generally the second stage has enough velocity (and acceleration) that shutting down thrust chambers might be more operable for the system than the complexity of throttling down to $10-20 \%$ of the original thrust level at sea level. Figure 7 illustrates this point with a thrust and acceleration versus time plot for the reusable booster and orbiter with external tank architecture.

Since the number of engines is chosen as six with one engine out capability, the design thrust level is $360 \mathrm{klbf}$ and the nominal operating thrust is $300 \mathrm{klbf}$ based on the GLOW determined in this study. This value drops as the mixture ratio shifts down after staging for the notional vehicle architectures. This off-design operation at the lower mixture ratios is well within current liquid propulsion design capability.

The exact numbers for these parameters would change during a detailed design phase, but they will remain close to these numbers and these were chosen for the conceptual design for this paper. 


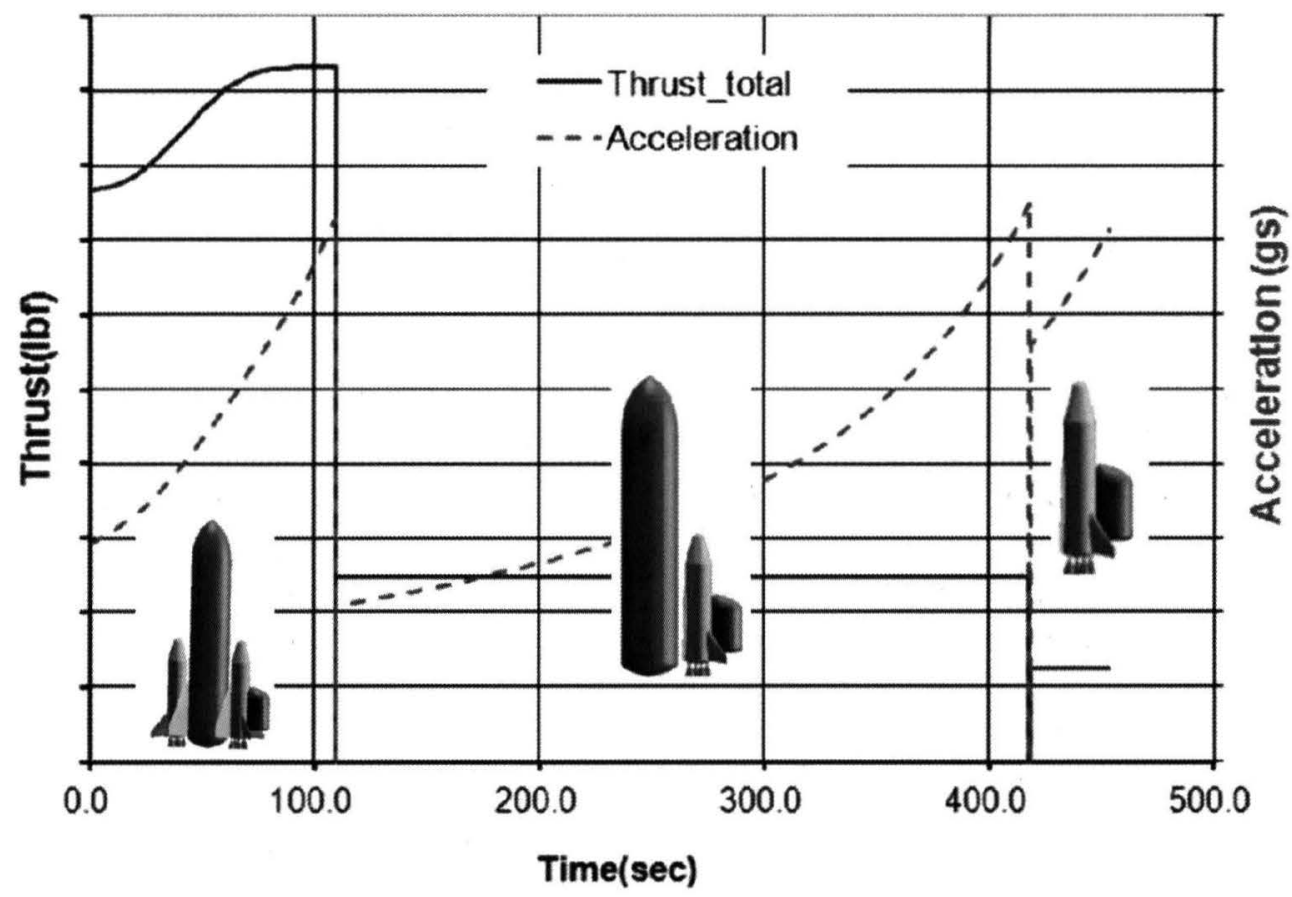

Figure 7. Notional Two-stage plus ET Architecture Thrust, Acceleration vs. Time

\section{Resulting Nominal Propulsion and Electric Power Generating System}

The result of the decisions discussed is shown as a functional schematic in Figure 8. This schematic represents the functions of maim propulsion, ACS/RCS propulsion, OMS propulsion,

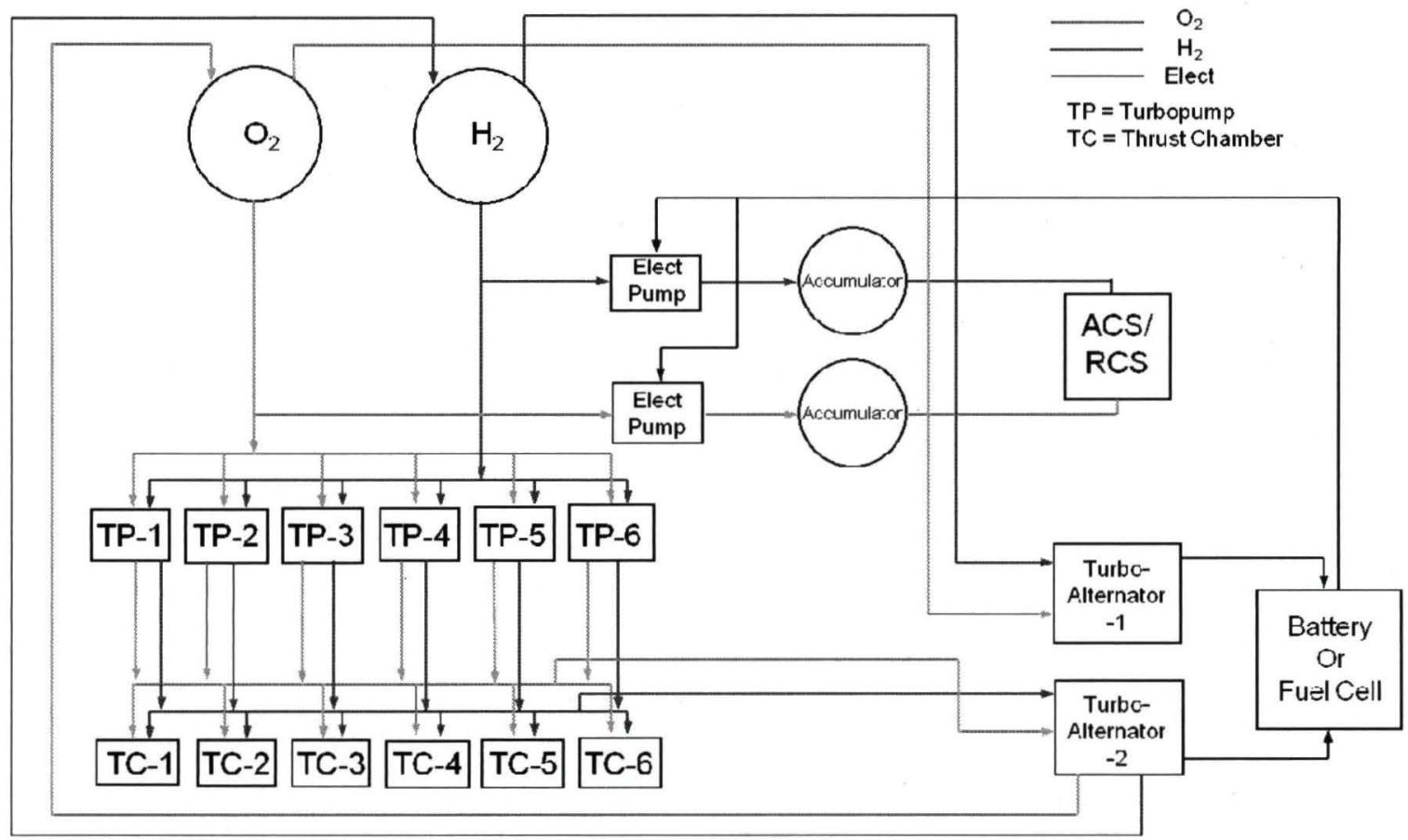

Figure 8. Functional Schematic of Propulsion and Electric Power Generation

This document does not contain ITAR or EAR Technical Information 
electrical power generation, and all propulsion and electrical power generation purging and pressurization for the entire vehicle. What have conventionally been separate systems are combined into one integrated system. Only two fluids are used - oxygen and hydrogen - which are initially stored only in the main propellant tanks and the ACS/RCS accumulators.

The integration of all these systems allows trades during design and development that would not have taken place under current practice where separate contracts and separate companies would have been responsible for each of the separate functions. The net effect is lowered overall development cost, much simplified operational logistics, and requirement flexibility in applying the fluids available to any propulsion or electric power generation tasks.

\section{Conclusions and Further Work}

This paper has shown that the propulsion choices made in Reference 1 to improve the affordability of the transportation architecture can be implemented. The engines will balance with the cycles chosen and produce reasonable and useable results with the chamber pressures, thrusts, and area ratios chosen. The internal engine parameters such as turbine inlet temperatures, pump discharge pressures, etc. are also reasonable. Furthermore, the integration of all these systems allows trades during design and development that would not have taken place under current practice where separate contracts and separate companies would have been responsible for each of the separate functions. The net effect is lowered overall development cost, much simplified operational logistics, and requirement flexibility in applying the fluids available to any propulsion or electric power generation tasks.

The analysis of the operationally efficient $\mathrm{LO}_{2} / \mathrm{LH}_{2}$ propulsion uncovered additional required vehicle/propulsion integration optimization. More detailed vehicle/propulsion integration will be one of the major focus areas in the next paper in this series. Subsequent papers will explore the vehicle design, the ground support system, and the operations aspects of the new delivery paradigm in greater detail.

\section{Acknowledgments}

The authors wish to acknowledge the many hours by Space Propulsion Synergy Team professionals who have volunteered their time, treasure, and talent over the many years of its existence. Without their many useful products, this paper could not have been undertaken. The authors would also like to thank Dr. Matthew R. Long of PWR and William Knuth for their substantive contributions to the paper. 


\section{References}

${ }^{1}$ McCleskey, C. M., Rhodes, R. E., Lepsch, R. A., Henderson, E. M., Robinson, J. W., “Approach to an Affordable and Productive Space Transportation System", AIAA-2012-4153, 48 ${ }^{\text {th }}$ AIAA/ASME/SAE Joint Propulsion Conference, Atlanta, Georgia, July 30 - August 1, 2012.

2 Joyner II, C., Levack, D., Rhodes, R., and Robinson, J., "Propulsion System Choices and Their Implications", AIAA-2010-6504. 46 ${ }^{\text {th }}$ AIAA/ASME/SAE/ASEE Joint Propulsion Conference, Nashville, Tennessee, July 25$28,2010$.

${ }^{3}$ Levack, D. J. H., Fully Integrated Scalable, Modular Two Fluid Propulsion and Power Module (IPPM) for Sustainable Architecture, NASA/CR-2007-215188, NASA Center for AeroSpace Information, Hanover, Maryland, December 2007.

${ }^{4}$ Harmon, T. J., Vilja, J. O., Briley, G. L., "The Operationally Efficient Propulsion System: A Perspective”, AIAA93-4221, AIAA Space Programs and Technologies Conference and Exhibit, Huntsville, Alabama, September 2123. 1993.

${ }^{5}$ Harmon, T., Erickson, C., Pauckert, R., "Operationally Efficient Space-Based Integrated Propulsion Module", 1992 JANNAF Propulsion Meeting, Indianapolis, Indiana, February 24-26, 1992. 